\title{
Elementos Neolamarckistas do Selecionismo Skinneriano
}

\author{
Carlos Eduardo Lopes \\ Universidade Estadual de Maringá \\ Carolina Laurenti \\ Universidade Estadual de Maringá
}

\begin{abstract}
RESUMO
A biologia evolutiva tem sido palco de um debate entre as teorias neodarwinista e neolamarckista. $\mathrm{O}$ neodarwinismo explica todo processo evolutivo em termos da seleção de variações genéticas randômicas, assim, o que acontece no âmbito da história de vida do indivíduo, no desenvolvimento e na aprendizagem, não interfere no curso evolutivo. Já a teoria neolamarckista defende a existência de múltiplas fontes de variação, nem sempre randômicas, sobre as quais a seleção opera; ela também admite que desenvolvimento e aprendizagem podem influenciar a evolução. O objetivo deste ensaio é mostrar que o modelo selecionista skinneriano apresenta características de uma teoria evolutiva neolamarckista. Conclui-se que essa aproximação ajudaria a análise do comportamento a participar ativamente de discussões contemporâneas da biologia evolutiva.
\end{abstract}

Palavras-chave: evolução; desenvolvimento; aprendizagem; comportamento; Skinner.

\begin{abstract}
Neo-Lamarckian elements of Skinnerian selectionism

Evolutionary biology has been a stage of debates between neo-Darwinian and neo-Lamarckian theories. Neo-Darwinism explains every evolutionary process in terms of the selection of random genetic variations. Thus, whatever takes place in the individual's life history, in its development and learning, does not interfere in the evolutionary course. Whereas, neo-Lamarckian theory upholds the existence of multiple sources of variation, not always random ones, on which selection operates; it also concedes that development and learning may influence evolution. The goal of this essay is to show that Skinner's model of selection displays features of a neo-Lamarckian evolutionary theory. It concludes that such approximation would help behavior analysis to actively participate in contemporary discussions about evolutionary biology.
\end{abstract}

Keywords: evolution; development; learning; behavior; Skinner.

Em diversos momentos de sua obra, Skinner apresenta analogias entre o condicionamento operante e a seleção natural (cf. Skinner, 1953, pp. 5455, 83, 90, 141; 1968, pp. 179-180; 1974, p. 205; 1972/1999, pp. 397-399). Embora haja controvérsias sobre quando exatamente tais analogias começaram a ser esboçadas (cf. Matos, 2003; Micheletto, Andery \& Sério, 2000), elas ganharam projeção e sistematização no clássico artigo Selection by consequences (Skinner, 1981). Nesse trabalho, os processos de variação e de seleção, utilizados por Darwin (1859/1998) para explicar a origem e a evolução de diferentes espécies, passam a explicar a origem e a evolução de estruturas anatômicas do organismo, de diferentes tipos de comportamento (reflexos, instintos e operantes) e de práticas culturais.
Essa interface com a biologia evolutiva, estabelecida de modo mais explícito pelo modelo de seleção pelas consequências, tem sido explorada em diferentes trabalhos, que discutem tanto as potencialidades (e.g. Hull, Langman \& Glenn, 2001), quanto os limites (e.g. Tavares, 2015; Tonneau \& Sokolowski, 2001) dessa relação. No entanto, existem controvérsias no terreno da biologia evolutiva (cf. Depew \& Weber, 1996; Jablonka \& Lamb, 2005; Pigliucci \& Müller, 2010), que ainda não foram consideradas de forma sistemática na discussão do alcance do selecionismo skinneriano. No contexto dessas questões da biologia contemporânea, um assunto que tem ganhado destaque diz respeito às limitações de uma teoria evolutiva centrada no gene, usualmente identificada com a versão contemporânea do neodarwinismo (cf. 
Jablonka \& Lamb, 2005; Odling-Smee, 2010; Pigliucci, 2009). De acordo com essa teoria, o processo evolutivo poderia ser integralmente explicado em termos de seleção natural de variações genéticas. Além disso, essas variações seriam completamente randômicas, o que quer dizer que suas causas seriam endógenas ou moleculares e, por isso, independentes do ambiente (Depew \& Weber, 1996; Mayr, 2004). Por conseguinte, para o neodarwinismo, a experiência ambiental do organismo (tanto no âmbito do desenvolvimento, quanto da aprendizagem) não interferiria no curso evolutivo da espécie (Jablonka \& Lamb, 2005; Pigliucci, 2009).

Críticas a essa teoria evolutiva têm levado a uma profunda mudança na forma de considerar a hereditariedade e, consequentemente, a evolução, ao ponto de alguns autores defenderem uma "nova síntese" (Jablonka \& Lamb, 2005, 2008a) ou uma "síntese estendida" (Pigliucci, 2009), em lugar da síntese moderna que consolidou o neodarwinismo. $\mathrm{O}$ argumento principal é que a seleção natural de variações genéticas deveria ser complementada pela seleção de outros tipos de variação ${ }^{1}$ (Jablonka \& Lamb, 2005, 2008b). Além disso, na medida em que todas essas fontes de variação sofrem, em algum grau, influência de processos que ocorrem no interior do próprio organismo e de mudanças ambientais (e, portanto, não são completamente randômicas), seria legítimo dizer que a experiência ambiental do organismo interfere no processo evolutivo, levando alguns autores a defender que o neodarwinismo poderia ser substituído por um neolamarckismo (Gissis \& Jablonka, 2011; Jablonka \& Lamb, 2005).

Essa temática tem relevância para a análise do comportamento, sobretudo para as discussões da proposta selecionista de Skinner, pois uma característica basilar da teoria evolutiva centrada no gene, ou seja, a defesa de que apenas variações genéticas randômicas têm relevância evolutiva, parece estar presente em muitas das analogias skinnerianas entre seleção natural, reforçamento operante e evolução cultural (cf. Skinner, 1971, p. 130; 1974, p. 36, 114; 1972/1999, p. 399; 1984b, p. 505; 1989, p. 115).

$\mathrm{Na}$ medida em que o neodarwinismo limita a evolução à seleção de variações genéticas randômicas, não haveria qualquer contribuição da análi- se do comportamento para a biologia evolutiva. Por outro lado, em uma perspectiva neolamarckista, a aprendizagem interfere no curso evolutivo e, portanto, a análise do comportamento, por meio do modelo de seleção por consequências, poderia participar ativamente das discussões da biologia evolutiva, esclarecendo, por exemplo, o papel do condicionamento operante na evolução.

Considerando essas possibilidades, o objetivo geral deste ensaio é situar o modelo selecionista de explicação do comportamento, proposto por Skinner, no debate atual entre neodarwinismo e neolamarckismo. Mais especificamente, o que se pretende mostrar é que, a despeito de apresentar algumas características de uma teoria evolutiva centrada no gene, o selecionismo skinneriano exibe elementos que o aproximariam de uma teoria neolamarckista da evolução.

\section{NEODARWINISMO COMO TEORIA EVOLUTIVA CEN- TRADA NO GENE}

O termo neodarwinismo foi originalmente cunhado por Romanes, em 1894, para designar um darwinismo sem a herança dos caracteres adquiridos (Mayr, 2004). No entanto, atualmente neodarwinismo é identificado com a síntese evolutiva moderna, que combinou a teoria da evolução pela seleção natural de Darwin com as descobertas da genética e da sistemática (Pigliucci, 2009; Ridley, 2008).

O neodarwinismo entende a evolução, estritamente, como a mudança na frequência dos genes de populações, sendo que o principal mecanismo dessa mudança é a seleção de variações genéticas randômicas. Essas variações genéticas, material da seleção, são randômicas, no sentido de não serem influenciadas diretamente pelo ambiente no qual o organismo está inserido, e de não serem planejadas ou dirigidas a um fim previamente determinado, seja ele a adaptação, a perfeição ou o progresso (Depew \& Weber, 1996; Ridley, 2008).

Uma das consequências dessa teoria evolutiva centrada no gene é o estabelecimento de uma relação unilateral entre evolução, desenvolvimento e aprendizagem (Jablonka \& Lamb, 2005). No desenvolvimento, o ambiente teria apenas a função de cenário para aquilo que já está pré-determinado nos genes se desenvolver ou se desenrolar (Lewontin, 1998/2000). $\mathrm{Na}$ aprendizagem, aquilo que é "adquirido" teria contribuições apenas para a relação do indivíduo com o ambiente no curso de sua história de vida, sendo inócuo 
do ponto de vista evolutivo. Assim, a experiência ambiental do organismo, no âmbito do desenvolvimento ou da aprendizagem, não teria qualquer impacto na evolução das espécies (Jablonka \& Lamb, 2005).

$\mathrm{O}$ que emerge é uma narrativa evolutiva em que o organismo é fechado, separado do seu ambiente, entendido apenas como um lócus de mutação e recombinação randômicas de genes: "o organismo é o objeto de forças evolucionárias, o nexo passivo de forças externas e internas independentes, uma gerando 'problemas' randômicos com respeito ao organismo, outra gerando 'soluções' randômicas com respeito ao ambiente" (Lewontin, 1998/2000, p. 47).

\section{NEOLAMARCKISMO COMO TEORIA EVOLUTIVA COMPLEXA}

Quando foi formulado, em 1885 pelo biólogo norteamericano Alpheus Packard, o termo neolamarckismo já exibia um uso heterogêneo (cf. Gissis, 2011; Jablonka \& Lamb, 2005). Contemporaneamente, neolamarckismo também designa um movimento multifacetado, mas tem em comum a defesa do caráter complexo do processo evolutivo, criticando a tentativa neodarwinista de reduzi-lo à seleção natural de variações genéticas completamente randômicas (Gissis \& Jablonka, 2011; Jablonka \& Lamb, 2005).

Diferente do que possa sugerir, o termo neolamarckismo não subscreve a tese de que haveria transferência direta de informação do fenótipo ao genótipo. Jablonka e Lamb (2005) esclarecem esse ponto: "Lamarckianos [contemporâneos] não fazem quaisquer declarações sobre a informação indo da proteína ao DNA, do produto para plano, do bolo para a receita. Estamos de acordo com Dawkins e Hull de que há boas razões para pensar que tal construção reversa pode ser muito difícil e, na maioria dos casos, improvável" (p. 361). Ademais, o neolamarckismo contemporâneo não é uma alternativa à seleção natural. Em outras palavras, ele não é uma tentativa de substituir o darwinismo, entendido como a teoria que explica a evolução das espécies por meio dos processos de variação e seleção natural, mas uma proposta de ampliar a compreensão do processo evolutivo para além da seleção de variações genéticas randômicas (Gissis \& Jablonka, 2011; Jablonka \& Lamb, 2005).

A concepção contemporânea de neolamarckismo destaca, ao menos, três aspectos, que marcam sua diferença em relação a uma teoria evolutiva neodarwinista. O primeiro deles é que o processo evolutivo envolveria múltiplas fontes de variações herdáveis sobre as quais a seleção natural operaria (Jablonka \& Lamb, 2005, 2008b). Com isso, essa teoria passa a considerar outros sistemas de herança, além do sistema genético.

O segundo ponto defendido por uma teoria evolutiva neolamarckista é que as múltiplas fontes de variação herdável não são integralmente randômicas, de modo que o ambiente no qual o organismo está inserido interfere nessas variações. Consequentemente, o ambiente não é apenas selecionador, mas também indutor de variações (Gissis, 2011; Jablonka \& Lamb, 2005).

O terceiro aspecto a ser destacado é que, diferentemente do que entende o neodarwinismo, o que acontece na relação entre organismo e ambiente, no desenvolvimento ou na aprendizagem, pode afetar o curso evolutivo (Gissis, 2011; Jablonka \& Lamb, 2005). Os diferentes sistemas de herança permitiriam, então, um cruzamento entre desenvolvimento, aprendizagem e evolução, uma vez que variações ocorridas durante o tempo de vida de um organismo poderiam ser transmitidas para futuras gerações.

Subjaz a essa nova visão a tese de que a relação entre organismo e ambiente é dinâmica: há uma abertura do organismo ao ambiente, no sentido de que o organismo é modificado na interação com o ambiente; e o organismo é ativo, ele age no mundo e aprende com o mundo (Odling-Smee, 2010).

\section{SELECIONISMO SKINNERIANO E NEOLAMARCKIS- MO CONTEMPORÂNEO}

Considerando as críticas dirigidas à teoria neodarwinista, o que se segue é uma discussão de afinidades entre o selecionismo skinneriano e uma teoria mais complexa da evolução, representada, aqui, pelas teses do neolamarckismo contemporâneo.

\section{A existência de variações não-randômicas}

A despeito das controvérsias sobre quando exatamente Skinner teria começado a explicar o comportamento em termos selecionistas (cf. Matos, 2003; Micheletto, Andery \& Sério, 2000), as analogias com a seleção natural apareceram mais explicitamente na obra skinneriana na década de 1950 (cf. Skinner, 1953, pp. $54-55,83,90,141$ ), tornando-se mais consistentes nas décadas de 1960 (cf. Skinner, 1968, pp. 179-180) e 1970 (cf. Skinner, 1974, p. 205; 1972/1999, pp. 397399). Isso quer dizer que o selecionismo skinneriano desenvolveu-se justamente no período de consolidação da síntese moderna, que está na base do neodarwinismo. 
Desse modo, não surpreende o fato de que a concepção de evolução mencionada por Skinner seja bastante próxima àquela apresentada pela teoria neodarwinista, que identifica filogênese com seleção natural de variações genéticas randômicas. Em vários textos, Skinner evidencia essa aproximação com o neodarwinismo. Por exemplo: "a origem de uma fantástica variedade de coisas vivas poderia ser explicada pela contribuição feita por novos fatores, possivelmente de proveniência randômica, à sobrevivência" (Skinner, 1974, p. 36); "o termo chave no título de Darwin é Origem. A novidade poderia ser explicada sem apelar a um planejamento prévio se mudanças randômicas na estrutura forem selecionadas por suas consequências" (Skinner, 1972/1999, p. 399). Tecendo paralelos com a seleção natural, Skinner estendeu a ideia de variação randômica para explicar a origem e a evolução de operantes (cf. Skinner, 1974, p. 114) e de práticas culturais (cf. Skinner, 1971, p. 130).

Até esse ponto, o selecionismo skinneriano aproxima-se da teoria neodarwinista da evolução no que se refere ao caráter randômico das variações. No entanto, Skinner $(1968,1971)$ parece admitir que nem todas as variações são randômicas, sugerindo a possibilidade de variações dirigidas ou induzidas pelo ambiente, sobretudo nos níveis ontogenético e cultural. Isso fica claro na discussão skinneriana dos ambientes indutores de criatividade no contexto educacional (cf. Skinner, 1968, pp. 176-183). Contingências sociais pouco aversivas e que não exigem um controle de estímulos muito rígido, maximizariam a ocorrência de comportamento novo ou de variações comportamentais. Além disso, uma cultura poderia evoluir mantendo esses ambientes como parte de práticas culturais (cf. Skinner, 1968, p. 183). Isso quer dizer que, pelo menos no caso do comportamento e da cultura, as variações não são necessariamente independentes ou "cegas" ao ambiente imediato, ao contrário, certos arranjos ambientais podem aumentar ou diminuir a produção de variações.

Mesmo no nível filogenético, Skinner (1984b) chegou a admitir que o ambiente poderia ter um papel indutor, e não apenas selecionador, de variações, afirmando que a "evolução pode ser acelerada por mudanças ambientais" (p. 508). Todavia, ele ainda parece reticente nesse ponto, pois logo complementa: "mas a essência da evolução é variação e reprodução em qualquer ambiente que se apresente" (p. 508). Isso porque a analogia com a concepção de variação genética randômica, típica do neodarwinismo, parece ter sido útil para que Skinner pudesse explicar a origem das variações no comportamento operante e em práticas culturais eliminando a teleologia. Dito de outro modo, Skinner (1981) parece sugerir que se não fossem randômicas, as variações genéticas aconteceriam para promover a adaptação do organismo às condições de vida em vigor. Raciocínio semelhante é estendido, então, ao comportamento operante e às práticas culturais; eles não são governados pelo futuro, mas por consequências que figuram necessariamente no passado, sejam elas reforçadoras, no caso do operante, ou consequências de sobrevivência do grupo, no caso da evolução de práticas culturais (Skinner, 1981).

Outro aspecto que parece estar presente no argumento skinneriano é de que a negação do caráter randômico das variações conduziria à ideia de planejamento (Skinner, 1981). Isso fica evidente no segundo e terceiro níveis de variação e de seleção: é possível induzir variações em operantes e em práticas culturais por meio do planejamento (cf. Skinner, 1971, pp. 145-183). Se esse argumento fosse válido, Skinner estaria correto em preservar o caráter randômico das variações no primeiro nível, pois, uma vez negado, isso abriria o flanco para a noção de um "planejador" na seleção natural.

No entanto, as críticas neolamarckistas ao caráter completamente randômico de variações genéticas não conduz à defesa de um "planejador", ou mesmo de uma explicação teleológica do processo evolutivo (Jablonka \& Lamb, 2005). Quando biólogos contemporâneos reconhecem que variações genéticas podem ser induzidas pelo ambiente, o que está sendo admitido é "que a evolução por seleção natural levou à construção de mecanismos que alteram o DNA em resposta a sinais que células recebem de outras células e do ambiente" (Jablonka \& Lamb, 2005, p. 88). Desse modo, o possível receio de Skinner (1981) em relação a um planejador não parece se justificar, pois a defesa neolamarckista da existência de variações genéticas dirigidas, ou parcialmente dirigidas pelo ambiente ${ }^{2}$, não é inconsistente com o darwinismo e, consequentemente, com o próprio selecionismo skinneriano.

\section{A relação entre desenvolvimento e evolução}

Se evolutivamente o ambiente funcionar apenas como selecionador de variações genéticas randômicas, o que acontecer durante a história de vida de um organismo, em termos de desenvolvimento e, principalmente, de aprendizagem, não terá qualquer relevância para o curso evolutivo (Gissis, 2011; Jablonka \& Lamb, 2005). Quando aplicado ao desenvolvimento, o neodarwinismo conduz, geralmente, a um tipo de pré-for- 
macionismo ${ }^{3}$, no qual se defende que o projeto completo do organismo, com toda informação necessária para especificá-lo, estaria contido nos genes e, portanto, o desenvolvimento seria o mero desdobramento de um programa genético inscrito no ovo fertilizado (Lewontin, 1998/2000).

No entanto, algumas objeções skinnerianas à noção de desenvolvimento mostram um posicionamento contrário ao pré-formacionismo, o que aproxima Skinner de críticos contemporâneos dessa concepção (e.g. Keller, 2000; Lewontin, 1998/2000). Por exemplo: "Desenvolver significa originalmente desdobrar, como alguém que desdobra uma carta. Assumimos que o que vemos estava lá desde o início. Como na evolução pré-darwinista (na qual evoluir significa desenrolar como alguém que desenrola um pergaminho), o desenvolvimentismo é uma forma de criacionismo" (Skinner, 1989, p. 16).

Um dos principais argumentos de Skinner (1981) é que o pré-formacionismo (ou desenvolvimentismo) adotaria um ponto de partida absoluto, à semelhança de uma causa iniciadora, incorrendo, por isso, em uma visão de causalidade típica da mecânica clássica. Tal como os críticos contemporâneos da noção de gene como estoque de informações (e.g. Keller, 2000; Lewontin, 1998/2000), Skinner (1981) rejeita a ideia de que o ponto de partida do desenvolvimento seria o material genético de um organismo:

Diz-se que genes e cromossomos "contêm as informações" necessárias para que o ovo fertilizado cresça até se tornar um organismo maduro. Mas uma célula não consulta um estoque de informações para aprender como mudar, ela muda por causa de fatores que são o produto de uma história de variação e de seleção, um produto que não é bem representado pela metáfora do armazenamento. (Skinner, 1981, p. 503)

Além disso, mesmo reconhecendo que não se preocupou de modo ostensivo com a acepção biológica de desenvolvimento (cf. Skinner, 1984b, p. 506), Skinner (1984a) destaca a participação do ambiente na constituição do organismo desde a concepção. Em uma réplica a Wahlsten, Skinner (1984a) diz: "eu concordo [com Wahlsten] que o ambiente de um organismo começa a agir assim que o organismo começa a existir" (p. 707). $\mathrm{Na}$ inter-relação com os genes, o ambiente participaria da especificação de estruturas anatomofisiológicas e também de comportamentos típicos da espécie. Skinner (1984a) admite também esse último ponto quando diz que "comportamento que parece ser instintivo pode ser modificado pela experiência" (p. 707).

A crítica ao pré-formacionismo genético e o reco- nhecimento do papel do ambiente no desenvolvimento aproximam Skinner de uma concepção epigenética de desenvolvimento, algo típico de autores considerados neolamarckistas (e.g. Gissis \& Jablonka, 2011; Jablonka \& Lamb, 2005). Atualmente, a epigenética é um ramo da biologia que estuda os mecanismos que tornam as células de um organismo comprometidas com uma forma ou função particular durante o desenvolvimento, bem como os processos responsáveis pela transmissão desse estado estrutural ou funcional nas linhagens celulares (Jablonka \& Lamb, 2002). Em outras palavras, os sistemas epigenéticos envolvem mecanismos que regulam e mantêm a expressão gênica ("ativando" e "desativando" genes, por exemplo), e processos de transmissão e herança desse estado de ativação ou desativação. Uma vez que a maioria desses sistemas são sensíveis a mudanças ambientais (como temperatura, alimentação, poluentes, interações sociais), a epigenética sustenta uma concepção de desenvolvimento antitética ao pré-formacionismo (Francis, 2011/2015; Lewontin, 1998/2000).

Mesmo não sendo uma disciplina nova, apenas recentemente a epigenética passou a ser considerada um ramo específico da biologia (Jablonka \& Lamb, 2002, 2008b), cujo interesse tem crescido nas últimas décadas (Francis, 2011/2015). Certamente, Skinner não acompanhou esses avanços, mas, de qualquer modo, não parece haver de antemão inconsistência entre o selecionismo skinneriano e as discussões contemporâneas da epigenética, inclusive em termos de seu papel na evolução (Schneider, 2007).

\section{0 organismo é ativo}

Em um texto publicado na década de 1960 , no qual discute as diferenças entre filogênese e ontogênese do comportamento, Skinner (1969) argumenta que a história ontogenética pode influenciar a história evolutiva de uma espécie. As contingências de reforçamento podem, por exemplo, ser responsáveis pela fixação de um grupo de organismos em um dado ambiente, de modo que a seleção natural passaria a agir nesse grupo de maneira específica. Nas palavras de Skinner (1969): “O comportamento que surge de contingências ontogenéticas pode tornar contingências filogenéticas mais ou menos efetivas. O comportamento ontogenético pode permitir que uma espécie se mantenha em um dado ambiente por muito tempo, tornando assim possível que contingências filogenéticas operem" (p. 203).

Essa afirmação é bastante consistente com a discussão contemporânea sobre a teoria da construção de ni- 
chos e seu impacto na evolução (cf. Odling-Smee, 2010; Shavit \& Griesemer, 2011). Nessa proposta, argumenta-se que os organismos têm um papel ativo no curso evolutivo, uma vez que, por meio do seu metabolismo, fisiologia e comportamento, eles constroem seu ambiente, ou, mais especificamente, um nicho ecológico (Shavit \& Griesemer, 2011). Com isso, seria legítimo dizer que os organismos criam não apenas soluções para problemas que encontram no ambiente, mas também novos problemas que terão de ser enfrentados por futuras gerações (Odling-Smee, 2010). Toda essa atividade do organismo interfere diretamente nas condições de vida e, consequentemente, interfere em como a seleção natural operará. Desse modo, a teoria de construção de nicho põe em xeque a máxima neodarwinista de que, evolutivamente, não é o organismo que se adapta ao ambiente, mas é o ambiente que seleciona os organismos mais adaptados.

Na NCT [niche construction theory] os ambientes seletivos dos organismos são, portanto, parcialmente determinados por fontes independentes de seleção natural, por exemplo, pelo clima ou por eventos físicos e químicos, como de costume. [Mas] eles também são parcialmente determinados pelo que os organismos fazem, ou previamente fizeram, sozinhos ou conjuntamente, com o ambiente, [ou seja] pela construção de nicho. (Odling-Smee, 2010, p. 176)

Haveria, portanto, uma reciprocidade entre o papel ativo do organismo e o caráter selecionador do ambiente. Assim, o comportamento não apenas interfere na evolução, mas de certa maneira a dirige, o que faz com que alguns autores vejam os modelos de construção de nichos como mais consistentes com neolamarckismo do que com o neodarwinismo (cf. Jablonka \& Lamb, 2005, p. 176).

Por outro lado, em alguns momentos, Skinner (1981) parece afirmar exatamente o oposto, sugerindo que a defesa da atividade do organismo em uma narrativa evolutiva seria uma insistência na noção de agente iniciador: "Tentamos identificar tal agente quando dizemos . . que uma espécie se adapta ao ambiente ao invés de [dizer] que o ambiente seleciona os traços adaptativos" (p. 504). No entanto, o contexto dessa discussão diz respeito à origem das espécies, do comportamento operante e de práticas culturais. $\mathrm{O}$ argumento skinneriano é de que explicar a origem negligenciando o papel seletivo do ambiente conduz ao agente iniciador nos diferentes níveis de variação e de seleção. Mas isso não significa que Skinner advoga uma visão de organismo passivo, ou um ambientalismo radical: "Um organismo é mais do que um corpo; ele é um corpo que faz coisas. Tanto órgão quanto organismo estão etimologicamente relacionados com trabalho. O organismo é o executor" (Skinner, 1989, p. 28). Essa ideia de organismo ativo ou executor não subscreve a tese do agente iniciador, pois tal atividade não se dá independente do ambiente, mas sim contextualizada nele. Trata-se, portanto, de recusar as teses tanto do agente iniciador quanto do "ambiente iniciador", em favor de um relacionismo, no qual a relação entre organismo executor e ambiente selecionador seria o ponto de partida para a construção de uma narrativa evolutiva. Dessa perspectiva, não haveria, pois, contradição em admitir o papel selecionador do ambiente e o caráter ativo do organismo.

\section{A ontogênese afeta a filogênese}

Mas recusar uma concepção pré-formacionista de desenvolvimento - admitindo, que o desenvolvimento não é um mero "desdobrar" de informações genéticas e que o organismo é ativo, ainda não é suficiente para aproximar o selecionismo skinneriano do neolamarckismo. Até porque embora a epigenética e a teoria de construção de nicho inspirem muitos neolamarckistas, algumas de suas descobertas não parecem incompatíveis com o neodarwinismo (Caponi, 2011; Lewontin, 1998/2002).

Talvez a característica mais evidente (e polêmica) do neolamarckismo seja a defesa de que a aprendizagem possa interferir na evolução. Essa tese permitiria, portanto, avaliar de maneira mais clara uma aproximação entre o modelo selecionista skinneriano e o neolamarckismo. Nos termos do selecionismo de Skinner, trata-se de indagar se a ontogênese poderia afetar a filogênese. Isso teria implicações importantes para a admissão do papel do comportamento na evolução: se a aprendizagem pode interferir na evolução, isso quer dizer que mudanças no comportamento individual deveriam ser consideradas na explicação do curso evolutivo de uma espécie.

De acordo com o neolamarckismo, há diferentes possibilidades da aprendizagem, ou mais especificamente, do comportamento aprendido interferir no curso evolutivo (Gissis \& Jablonka, 2011; Jablonka \& Lamb, 2005). Uma delas diz respeito ao fato de que um comportamento ontogenético pode estar na origem de um comportamento filogenético. Outra é a possibilidade de um comportamento aprendido transformar-se em uma tradição cultural. Ambas as possibilidades parecem ser endossadas pela explicação selecionista skinneriana. 


\section{a. Comportamento aprendido como origem de um comporta- mento instintivo}

Ao discutir de forma explícita as possíveis relações entre ontogênese e filogênese, Skinner (1969) admite que a evolução de um comportamento instintivo, ou de um comportamento típico de uma espécie, poderia ter origem em um comportamento operante. Para desenvolver esse ponto, Skinner discutiu como o comportamento inato do cão de dar voltas em torno de si, antes de se deitar, poderia ter aparecido inicialmente como um operante:

Suponhamos que um cão não possua uma tendência instintiva de dar voltas em torno de si quando se deita, mas que o deitar-se dessa maneira é reforçado como um operante pela produção de um leito mais confortável. Se não há nenhuma vantagem filogenética, presumivelmente a prontidão com que a resposta é aprendida não será afetada pela seleção. Mas vantagens filogenéticas podem ser imaginadas: esse leito pode ser mais livre de insetos, oferecer uma melhor visibilidade de predadores ou presas, permitir movimentos mais rápidos em uma emergência, $\mathrm{e}$ assim por diante. Cães nos quais a resposta foi condicionada mais prontamente, devem ter tido mais chances de sobreviver e procriar [...]. Girar em torno de si antes de deitar pode ter se tornado tão prontamente disponível como um operante que finalmente apareceu sem reforçamento. Era então "instintivo". Contingências ontogenéticas foram responsáveis pela topografia de uma resposta herdada. (Skinner, 1969, p. 204)

Da mesma forma, Jablonka e Lamb (2005) apresentam uma série de casos em que comportamentos originalmente aprendidos teriam se tornado inatos, como, por exemplo, o canto de certos pássaros e a configuração de padrões de corte e acasalamento (cf. Jablonka \& Lamb, 2005, pp. 286-290). À semelhança de Skinner, elas concluem que "[...] a seleção natural pode converter o que era originalmente uma resposta aprendida no ambiente em comportamento inato" (p. 285).

A busca por uma explicação dessa "transformação" de comportamentos aprendidos em comportamentos instintivos tem levado ao resgate de propostas alternativas sobre a genética, que, no contexto da síntese moderna, foram rechaçadas ou simplesmente ignoradas (Jablonka \& Lamb, 2005; Palmer, 2011). Um exemplo emblemático é a noção de assimilação genética ${ }^{4}$ proposta inicialmente por Conrad H. Waddington (19051975).

Nesse ponto parece haver uma convergência explícita entre selecionismo skinneriano e neolamarckismo contemporâneo, uma vez que o próprio Skinner (1969) admite que a explicação de como um comportamento operante pode dar origem a um comportamento instintivo foi inspirada nos estudos de Waddington, em especi- al, em um dos seus exemplos que ilustram como "calosidades úteis no peito de um avestruz, presumivelmente de origem ontogenética, aparecem antes do ovo eclodir porque uma tendência a formar calosidades evoluiu ao ponto da variável ambiental (fricção) não ser mais necessária” (p. 204).

\section{b. Comportamento aprendido como origem de uma tradição cultural}

Outra possibilidade de um comportamento aprendido ter impacto evolutivo é quando ele constitui uma tradição cultural (Jablonka \& Lamb, 2005). Um exemplo pode esclarecer esse ponto ${ }^{5}$. Um grupo de organismos avança para um novo território em busca de novas fontes de alimentação, uma vez que o ambiente em que geralmente vivem começa a sofrer escassez de alimento. Se um indivíduo desse grupo for capaz de aprender um comportamento novo, que o permita acessar uma nova fonte de alimento, como descascar uma pinha e obter suas sementes nutritivas, é evidente que esse organismo e até mesmo sua prole terá mais chances de sobreviver nesse novo ambiente. No entanto, se esse comportamento novo não puder ser transmitido adiante, quando o indivíduo morrer tudo começa "do zero", exigindo que outro membro do grupo aprenda como acessar as sementes, o que pode nunca acontecer.

Desse modo, o comportamento aprendido só poderá ter impacto evolutivo quando for transmitido de uma geração a outra (Jablonka \& Lamb, 2005; OdlingSmee, 2010). Voltando ao exemplo, tudo será diferente se a prole não apenas se beneficiar do comportamento da mãe que sabe abrir pinhas, mas também for capaz de aprender com ela como abri-las. Nesse caso, o impacto evolutivo do comportamento aprendido parte da capacidade de aprendizagem social, algo bem documentado em diversas espécies de peixes, aves e mamíferos (cf. Brown \& Laland, 2003; Galef Jr. \& Laland, 2005). Isso quer dizer que, pelo menos nessas espécies, comportamentos aprendidos podem ser transmitidos diretamente de um indivíduo a outro. Além disso, diferente da herança genética, a "herança comportamental" não se restringe a indivíduos de uma mesma linhagem, podendo envolver até mesmo organismos de espécies diferentes (cf. Jablonka \& Lamb, 2005, pp. 188-189, 233-235).

No entanto, a capacidade de aprendizagem social ainda não é suficiente para garantir que um comportamento aprendido tenha impacto evolutivo, pois, "a maioria das inovações comportamentais são efêmeras de modo que sequer conseguem se estabelecer, e muito menos se difundir em uma população" (Jablonka \& 
Lamb, 2005, p. 176). Portanto, a relevância evolutiva de variações comportamentais aprendidas depende também da estabilidade do ambiente social, o que só pode ser alcançado no contexto de uma cultura. Isso parece ser endossado por Skinner (1981), na medida em que admite que a "transmissão" do operante só acontece no sentido de ele se manter como parte do repertório de um indivíduo. Apenas quando se torna uma prática cultural, o operante poderia se difundir e afetar a população.

Se o comportamento aprendido só pode ter impacto evolutivo em uma cultura, o alcance desse impacto depende da definição de cultura. Dito de outro modo, se a cultura for um tipo de grupo social exclusivamente humano, apenas nessa espécie a "herança comportamental" poderia ter relevância evolutiva. Por outro lado, quando se adota uma definição de cultura mais inclusiva, a explicação neolamarckista da evolução pode ser ampliada para várias espécies. Seguindo essa possibilidade, Jablonka e Lamb (2005) definem cultura como: "um sistema de padrões de comportamento, preferências e produtos de atividade animal transmitidos socialmente que caracterizam um grupo de animais sociais" (p. 160). Na medida em que esses padrões estão sujeitos a sofrer variações durante a transmissão, seria possível falar de uma evolução cultural, compreendida como "a mudança, ao longo do tempo, na natureza e frequência de preferências, padrões ou produtos do comportamento socialmente transmitidos em uma população" (p. 160). Dessa maneira, se o ambiente em que a cultura evolui for suficientemente estável, uma "tradição cultural" pode ser criada, ou seja, um conjunto de formas de comportamento é transmitido de geração para geração por aprendizagem social, difundindo-se e tornando-se típico daquele grupo.

Skinner (1989) define cultura como "contingências de reforçamento mantidas por um grupo" (p. 52). Essa definição não restringe cultura à espécie humana. Uma prova disso é que, logo depois de apresentar essa definição, Skinner menciona o caso dos macacos da ilha de Koshima para ilustrar a constituição da prática cultural de lavar batatas no mar. O mesmo exemplo é discutido por Jablonka e Lamb (2005, pp. 178-180) como um caso de difusão de um comportamento aprendido em uma cultura de animais não-humanos. Além disso, Skinner (1981) nega a identificação entre nível cultural e comportamento verbal: "Eu não trato cultura . . . 'como se fosse idêntica ao comportamento verbal'. Eu disse que o comportamento verbal ampliou enormemente a importância de um terceiro tipo de seleção pelas con- sequências" (p. 504). De modo semelhante ao neolamarckismo contemporâneo (cf. Jablonka \& Lamb, 2005, pp. 172-176), Skinner (1981) admite que há formas não-verbais de aprendizagem social que podem ter relação com a evolução cultural: "Outras maneiras em que novas formas de comportamento são transmitidas a novos membros do grupo incluem imitação e modelação" (p. 504).

Se não há uma identificação entre comportamento verbal e cultura, seria possível considerar uma cultura não-verbal e, em última instância, admitir a possibilidade da constituição de uma tradição cultural mesmo em animais não-humanos (Jablonka \& Lamb, 2005, pp. 176-180). Em Walden two, Skinner (1948/2005) descreve explicitamente um caso de constituição de uma tradição em animais não-humanos. O exemplo é de um rebanho de ovelhas que aprendeu a evitar uma cerca elétrica (por reforçamento negativo). Depois de algum tempo, a cerca foi substituída por uma corda, que continuou a ser evitada pelos animais; mas, "o curioso é que a maioria dessas ovelhas nunca levou choque da cerca. A maioria delas nasceu depois que tiramos a cerca. Tornou-se tradição [itálicos adicionados] entre nossas ovelhas nunca se aproximar da corda. Os cordeiros adquiriram isso com os mais velhos" (p. 16).

Assim, não é a existência da cultura ou mesmo de evolução cultural que diferencia humanos de não-humanos. A diferença estaria nos modos como informações são organizadas, transferidas e adquiridas em uma cultura humana. Diferente do que acontece em "culturas animais", a informação cultural humana envolve símbolos, principalmente na forma de palavras em uma linguagem. Em suma, "é nossa habilidade de pensar e comunicar-se por meio de palavras e outros tipos de símbolos que nos torna tão diferentes" (Jablonka \& Lamb, 2005, p. 193). Em termos skinnerianos, isso teria paralelos com o comportamento verbal, que ampliaria os efeitos da aprendizagem social. Para ilustrar isso, Skinner (1989) dá o exemplo do comportamento de apagar fogo com água. Ele pode surgir, acidentalmente, como uma variação no comportamento de um indivíduo. Ao produzir uma consequência reforçadora negativa (eliminar o fogo), o comportamento pode ter se mantido no repertório do indivíduo em condições semelhantes. Mas, se as condições para a execução desse comportamento forem raras - como ter disponível uma fonte de água no momento de um novo incêndio -, o comportamento dificilmente se difundirá em uma cultura não-verbal. Para tanto, seria necessário que alguém extinguisse o fogo com água de maneira frequente $\mathrm{e}$ 
conspícua, de modo que outros pudessem imitar e ficar sob controle dos mesmos tipos de consequências, o que tornaria esse operante uma prática cultural transmitida de geração para geração por modelação e imitação: “A prática difundir-se-ia mais rapidamente quando a outros for mostrado como extinguir o fogo" (p. 117). Com o comportamento verbal, a difusão da prática torna-se muito mais rápida e completamente independente das condições originais, ou seja, para ensinar a um conjunto de pessoas como apagar fogo com água não é preciso mostrar como fazer, basta "dizer a eles como fazê-lo" (p. 117).

Além disso, o comportamento verbal ou, nas palavras de Jablonka e Lamb (2005), a capacidade simbólica, que depende fortemente desse comportamento, não só amplia as possibilidades de transmissão de variações comportamentais, mas cria novas formas de variação, agora simbólicas (ou verbais). Desse modo, a evolução de uma cultura simbólica não se resume a uma "recapitulação linguística" de uma história evolutiva pré-linguística, mas algo de novo se produz. Isso quer dizer que o comportamento verbal cria novas relações, novas possibilidades de o indivíduo se relacionar com os outros, com o ambiente natural e também com ele mesmo, como é o caso do autoconhecimento ou da consciência (Skinner, 1981).

Em suma, a relação entre evolução cultural e evolução filogenética se dá por meio da constituição de tradições culturais, entendidas como um estilo de vida adquirido e transmitido entre gerações de uma população, o que cria especificidades que podem interferir no processo de evolução da espécie. No caso de Skinner (1971), a relação entre evolução filogenética e cultural é considerada recíproca. De um lado, ele afirma que "a capacidade de passar pelas alterações de comportamento que tornam possível uma cultura foi adquirida na evolução da espécie" (p. 129). Isso quer dizer que a evolução filogenética foi responsável pelo desenvolvimento de comportamentos (operantes), susceptibilidades (sensibilidade às consequências) e processos (imitação, modelação, condicionamento operante), que tornaram possível a evolução cultural. Por outro lado, "reciprocamente, a cultura determina muitas das características biológicas transmitidas" (p. 129). Assim, uma cultura (principalmente quando é verbal ou simbólica) pode criar condições de sobrevivência e reprodução específicas e, até mesmo, impossíveis de existir fora dessa cultura (cf. Skinner, 1971, pp. 129-130).

\section{CONCLUSÃO}

O modelo selecionista skinneriano apresenta alguns elementos consistentes com o neolamarckismo contemporâneo. Em primeiro lugar, Skinner (1981) não apenas admite uma multiplicidade de fontes de variação (de origem filogenética, ontogenética e cultural), mas sustenta que, até certo ponto, essas variações podem ser induzidas pelo ambiente (Skinner, 1968, 1984b). Em segundo lugar, Skinner $(1981,1989)$ é um crítico explícito de uma concepção pré-formacionista de desenvolvimento, que estaria presente em narrativas evolutivas genocêntricas. Em terceiro lugar, o texto skinneriano tem uma abertura para a defesa de uma concepção de organismo ativo, desde que se reconheça o relacionismo como alternativa à dicotomia agente iniciador versus ambiente iniciador (Skinner, 1989). Em quarto lugar, o selecionismo skinneriano parece admitir a possibilidade de interferência da aprendizagem no curso evolutivo, aceitando tanto que um comportamento operante pode estar na base de um comportamento instintivo (Skinner, 1969), quanto que comportamentos operantes podem dar origem a tradições culturais difundidas pelo grupo de forma verbal (regras, máximas, instruções) ou não-verbal (imitação, modelação) (Skinner, 1981, 1984b).

Essas aproximações entre neolamarckismo e selecionismo skinneriano abrem um caminho promissor para que a análise do comportamento participe mais diretamente de debates atuais da biologia evolutiva. Aliás, um convite que já foi feito pelos neolamarckistas: "Cada vez mais biólogos estão insistindo que o conceito de hereditariedade atualmente usado no pensamento evolucionário é muito estreito, e que deve ser ampliado para incorporar os resultados e ideias advindos da biologia molecular e das ciências comportamentais" (Jablonka \& Lamb, 2005, p. 10). Novamente, isso parece convergir com a proposta selecionista de Skinner, na qual a interdisciplinaridade tornou-se inevitável: "a história completa será, finalmente, contada pela ação conjunta das ciências da genética, do comportamento e da cultura" (Skinner, 1989, p. 56).

\section{REFERÊNCIAS}

Brown, C., \& Laland, K. N. (2003). Social learning in fishes: A review. Fish and Fisheries, 4, 280-288.

Caponi, G. (2011). Aproximação epistemológica à biologia evolutiva do desenvolvimento. In P. C. Abrantes et al. (Orgs.), Filosofia de biologia (pp. 211-123). Porto Alegre: Artmed. 
Darwin, C. (1998). The origin of species. London: Wordsworth Editions. (Trabalho original publicado em 1859)

Depew, D. J., \& Weber, B. H. (1996). Darwinism evolving: Systems dynamics and genealogy of natural selection. Cambridge: The MIT Pres.

Francis, R. C. (2015). Epigenética: Como a ciência está revolucionando o que sabemos sobre a hereditariedade (I. W. Kuck, Trans.). Rio de Janeiro: Zahar. (Trabalho original publicado em 2011)

Galef Jr., B. G., \& Laland, K. N. (2005, June). Social learning in animals: Empirical studies and theoretical models. BioScience, 55(6), 489-499.

Gissis, S. B. (2011). Introduction: Lamarckian problematics in historical perspective. Transformations of lamarckism: From subtle fluids to molecular biology (pp. 21-32). Cambrigde, MA: The MIT Press.

Gissis, S. B., \& Jablonka, E. (Eds.). (2011). Transformations of lamarckism: From subtle fluids to molecular biology. Cambrigde, MA: The MIT Press.

Hull, D., Langman, R. E., \& Glenn, S. S. (2001). A general account of selection: Biology, immunology, and behavior. Behaviorial and Brain Sciences, 24, 511-573.

Jablonka, E., \& Lamb, M. (2002). The changing concept of epigenetics. Annals New York Academy of Sciences, 981, 82-96.

Jablonka, E., \& Lamb, M. (2005). Evolution in four dimensions: Genetic, epigenetic, behavioral, and symbolic variation in the history of life. Cambridge, MA: MIT Press.

Jablonka, E., \& Lamb, M. (2008a). The epigenome in evolution: Beyond the modern synthesis. Vavilov Journal of Genetics and Breeding, 12(1/2), 242-254.

Jablonka, E., \& Lamb, M. (2008b). Soft inheritance: Challenging the modern synthesis. Genetics and Molecular Biology, 31(2), 389-395.

Keller, E. F. (2000). The century of the gene. Cambridge: Harvard University Press.

Lewontin, R. (2000). The triple helix: Gene, organism, and environment. Cambridge: Harvard University Press. (Trabalho original publicado em 1998)

Matos, M. A. (2003). A propósito de "a construção de seleção por conseqüências no trabalho de B. F. Skinner" (Andery, Micheletto e Sério, 2000). ABPMC Contexto, 23, 4-6.

Mayr, E. (2004). What makes biology unique? Considerations on the autonomy of a scientific discipline. New York: Cambridge University Press.

Micheletto, N., Andery, M. A. P. A., \& Serio, T. M. A. P. (2000). A construção do modelo de seleção por consequências no trabalho de B. F. Skinner. ABPMC Contexto, 21, 11-12.

Odling-Smee, J. (2010). Niche inheritance. In M. Pigliucci \& G. B. Müller (Eds.), Evolution: The extended synthesis (pp. 175-207). Cambridge, MA: The MIT Press.

Palmer, A. R. (2011). Developmental plasticity and the origin of novel forms: Unveiling cryptic genetic variation via "use and disuse". Journal of Experimental Zoology (Molecular and developmental evolution), 314b, 1-14.
Pigliucci, M. (2009, June). An extended synthesis for evolutionary biology. Annals of the New York Academy of Sciences, The Year in Evolutionary Biology, 1168, 218-228.

Pigliucci, M., \& Müller, G. B. (2010). Evolution: The extended synthesis. Cambrigde: The MIT Press.

Ridley, M. (2008). Evolução (3a ed.) (H. B. Ferreira, L. Passaglia \& R. Fischer, Trans.). Porto Alegre: Artmed. (Trabalho original publicado em 2004)

Schneider, S. M. (2007, Spring). The tangled tale of genes and environment: Moore's the dependent gene: The fallacy of "nature vs. nurture". Behavior Analyst, 30(1), 91105.

Shavit, A., \& Griesemer, J. (2011). Mind the gaps: Why are niche construction models so rarely used? In S. B. Gissis \& E. Jablonka (Eds.), Transformations of lamarckism: From subtle fluids to molecular biology (pp. 307-317). Cambrigde, MA: The MIT Press.

Skinner, B. F. (1953). Science and human behavior. New York: The MacMillan Company.

Skinner, B. F. (1968). The technology of teaching. New York: Appleton-Century-Crofts.

Skinner, B. F. (1969). The phylogeny and ontogeny of behavior. In Contingencies of reinforcement: A theoretical analysis (pp. 172-217). New York: Appleton-CenturyCrofts.

Skinner, B. F. (1971). Beyond freedom and dignity. New York: Alfred A. Knopf.

Skinner, B. F. (1974). About behaviorism. New York: Alfred A. Knopf.

Skinner, B. F. (1981). Selection by consequences. Science, 213(4507), 501-504.

Skinner, B. F. (1984a). Phylogenic and ontogenic environment. The Behavioral and Brain Sciences, 7(4), 701-711.

Skinner, B. F. (1984b). Some consequences of selection. The Behavioral and Brain Sciences, 7(4), 502-510.

Skinner, B. F. (1989). Recent issues in the analysis of behavior. Columbus: Merrill Publishing Company and Bell \& Howell Information Company.

Skinner, B. F. (1999). A lecture on "having" a poem. In J. S. Vargas (Ed.), Cumulative record: Definitive edition ( $\mathrm{pp}$. 391-401). Acton, MA: Copley Publishing Group. (Trabalho original publicado em 1972)

Skinner, B. F. (2005). Walden two. Indianapolis: Hackett Publishing Company, Inc. (Trabalho original publicado em 1948)

Tavares, C. E. (2015). Seleção natural e seleção por consequencias: Estudo sobre a transposição da teoria evolutiva selecionista à análise do comportamento de B. F. Skinner. (Dissertação de mestrado). Universidade de São Paulo, São Paulo.

Tounneau, F., \& Sokolowski, M. B. C. (2001). Is operant selectionism coherent? Behaviorial and Brain Sciences, 24, $558-559$.

Waddington, C. H. (1953, June). Genetic assimilation of acquired character. Evolution, 7(2), 118-126. 
Recebido em:24/06/2016

Primeira decisão editorial em:18/10/2016

Aceito em:25/10/2016

Notas:

1 De acordo com essa proposta, as variações epigenéticas, comportamentais e simbólicas também devem ser consideradas na evolução. Em todas essas dimensões, a experiência ambiental do organismo influenciaria no curso evolutivo. Mesmo as variações genéticas nem sempre são completamente randômicas (cf. Jablonka \& Lamb, 2005, pp. 83-101). No tocante às variações epigenéticas, os sistemas de herança dessa dimensão evolutiva mostram como variações fenotípicas, adquiridas no nível do desenvolvimento, que não envolvem mudanças na estrutura do DNA, podem ser passadas às gerações seguintes, tendo, portanto, repercussão evolutiva (pp. 113-154). Com respeito às variações comportamentais, admite-se que o comportamento adquirido, principalmente no campo da aprendizagem social, pode mudar os rumos evolutivos quando se torna uma "tradição cultural", criando um novo estilo de vida (pp. 155-191). No caso da variação simbólica, a interação humana social, permeada pela linguagem, ajudaria a construir novos "nichos sociais", passados de geração a geração, em um sistema de herança simbólica; isso tornaria a evolução humana extremamente complexa e fortemente influenciada pela evolução de práticas culturais (pp. 193-231).

2 Vale ressaltar que neolamarckismo contemporâneo não nega a existência de variações randômicas, mas sim a tese neodarwinista de que todas as variações, com impacto evolutivo, são randômicas (Jablonka \& Lamb, 2005).

3 Trata-se de uma teoria que originalmente defendia a tese de que um organismo completo, em miniatura, estaria presente no gameta masculino, e os ambientes intra e extrauterino forneceriam apenas as condições necessárias para o crescimento (desenvolvimento) desse ser em miniatura (Lewontin, 1998/2000).

4 De acordo com essa concepção, uma característica fenotípica, inicialmente produzida em resposta a alguma demanda ambiental, pode acabar sendo mantida (assimilada) no próprio genótipo de uma espécie se as condições seletivas se mantiverem suficientemente estáveis. Desse modo, quando há assimilação genética, o estímulo ambiental já não seria mais necessário (pelo menos não com a mesma intensidade e frequência) para constituir a mudança no fenótipo. Isso seria uma explicação possível da herança de um caractere adquirido (cf. Waddington, 1953).

5 Esse exemplo é baseado em uma invasão de ratos negros (Rattus rattus) ocorrida em uma floresta de Jerusalém, investigada por Ran Aisner e Yosi Terkel, citado por Jablonka e Lamb (2005) e Galef Jr. e Laland (2005). 